\title{
O ENSINO DE HISTÓRIA DA EDUCAÇÃO NA FORMAÇÃO DE PROFESSORES NO BRASIL ATUAL ${ }^{1}$
}

\author{
Bruno Gonçalves Borges ${ }^{2}$ \\ Décio Gatti Júnior ${ }^{3}$
}

\begin{abstract}
RESUMO
Trata-se da comunicação de resultados de pesquisa sobre a situação atual do ensino de História da Educação no Brasil, subsidiado pelo exame do percurso histórico da disciplina, a partir de bibliografia produzida desde meados da década de 1980, bem como pela consulta a 124 programas de ensino colhidos junto a 55 instituições de educação superior no país, no período compreendido entre 2000 e 2008. Pesquisa realizada no interior do Grupo de Estudos e Pesquisas sobre a Disciplina História da Educação (GEPEDHE), ocupando-se, em um primeiro momento, das questões de identidade e perfil programático assumidos/construídos pela disciplina, analisando, assim, a origem; a denominação; os objetivos do ensino; o perfil docente; a bibliografia e a seleção de conteúdos; para então, apresentar a discussão sobre a presença e as formas de organização da disciplina, em que foram analisados o regime de oferecimento; a carga horária definida para a disciplina; as ementas dos programas e as formas de oferta. Por fim, passa-se para a análise da situação do ensino de História da Educação quanto a sua consolidação, secundarização, estabilização e subsistência nos currículos dos cursos de formação de professores.

Palavras-Chave: História da Educação; Disciplina Escolar; Formação de Professores
\end{abstract}

\section{THE TEACHING OF THE HISTORY OF EDUCATION IN THE TRAINING AND EDUCATION OF TEACHERS IN BRAZIL CURRENTLY}

\begin{abstract}
This study communicates the results of investigation regarding the current situation of the teaching of the History of Education in Brazil, complemented by the examination of the historical course of the subject, based on the bibliography produced since the middle of the 1980 s, as well as by consultation of 124 teaching programs from 55 institutions of higher education in the country, in the period from 2000 to 2008. This is a study undertaken within the Group of Studies and Research regarding the Subject of History of Education (Grupo de Estudos e Pesquisas sobre a Disciplina História da Educação - GEPEDHE), concerning, at first, questions of the programmatic identity and profile assumed/constructed by the subject, thus analyzing the origin, the name, the teaching objectives, the teaching profile, the bibliography and the selection of content so as to then present the discussion regarding the presence and the forms of organization of the subject, in which were analyzed the system in which it is offered (length of the course), the number of class hours defined for the subject, the summaries of the programs and the forms in which it is offered. Finally, it passes on to analysis of the situation of the teaching of the History of Education in regard to its consolidation, secondarization, stabilization and subsistence in the curriculum of teacher education courses.
\end{abstract}

Keywords: History of Education; School Subject; Teacher Education 


\section{Introdução}

Inserido na temática da história das disciplinas, este texto objetiva comunicar os resultados alcançados em investigação sobre a situação atual da disciplina História da Educação nos cursos de formação de professores, por meio do exame das condições de oferta, sua relação com o currículo, os regimes de oferecimento e as finalidades propostas para o componente curricular no que se refere à formação de profissionais da educação.

No processo de pesquisa, constatou-se a centralidade ocupada pelo Curso de Pedagogia na oferta da disciplina História da Educação, enquanto nas demais licenciaturas o nível de oferta atualmente é incipiente ${ }^{4}$. Desse modo, a análise esteve concentrada sobre o Curso de Pedagogia, por meio da consulta aos programas de ensino, quadros curriculares e currículo dos docentes afetos a 55 cursos de graduação em Pedagogia de instituições das esferas federal (32), estadual (9), confessional e particular (14), localizadas nas regiões Sul (9), Sudeste (23), Nordeste (12), Norte (5) e Centro-Oeste (6) do Brasil, totalizando 124 programas, no período compreendido entre os anos de 2000 a 2008.

Assim, esta investigação constatou forte presença da disciplina nos cursos de formação de professores, em especial, para as séries iniciais do ensino fundamental brasileiro, mas, mesmo assim, manteve a concordância com a proposição geral de Escolano Benito (1994, p. 56), na qual se constata "[...] um estado internacional de crise da História da Educação como disciplina formativa", o que pode ser examinado em um contexto internacional no qual a disciplina vem sendo secundarizada, bem como em problemática mais geral, na qual se percebe um distanciamento inadequado entre a fecundidade dos resultados das pesquisas mais recentes e os conteúdos disseminados nas salas de aula dos cursos de formação de professores.

Justifica-se a seleção das instituições pesquisadas, pela adoção dos seguintes critérios: instituições qualificadas como universidades, tanto públicas quanto privadas; instituições/universidades que tenham cursos de formação de professores e, a princípio, todas as licenciaturas ${ }^{5}$; instituições/universidades que tenham programas de Pós-Graduação em Educação; instituições/universidades dedicadas essencialmente às ações de ensino, de graduação e pós-graduação Lato Sensu (especialização) que apresentam destaque, seja na quantidade de alunos, cursos, campus, entre outras características.

Pela quantidade de instituições pesquisadas (55 no total, responsáveis pela oferta de 124 disciplinas afetas à História da Educação), optou-se pela utilização preferencial dos planos de curso, acompanhados das estruturas curriculares e dos currículos dos docentes e, mediante a disponibilidade, acolheram-se também os projetos pedagógicos dos cursos. A busca pelo material analisado concretizou-se por meio da consulta as páginas 
eletrônicas das instituições de educação superior pesquisadas, do contato direto com os responsáveis acadêmicos das instituições, por e-mail e, em algumas situações, por telefone e fax.

Para a realização da pesquisa, partiu-se da leitura e interpretação dos programas de disciplina/planos de ensino, com apoio dos projetos pedagógicos (quando disponibilizados pelas instituições), quadros/fluxogramas de disciplinas e levantamento dos livros/manuais de ensino indicados, a fim de compor um quadro geral da situação da disciplina a partir dos seguintes itens: denominação, regime de oferecimento, carga horária, seriação, pré-requisitos, objetivos, ementas, seleção de conteúdos, matriz epistemológica, indicação bibliográfica, métodos de ensino e avaliação. Posteriormente, estes elementos foram analisados a partir das categorias de: identidade, perfil programático, presença e formas de organização.

Do ponto de vista metodológico trabalhou-se com o emprego das categorias de presença, identidade, normas e finalidades, perfil docente e discente, perfil programático e materiais pedagógicos (SANTOS, 2007b, p. 97) em sua vinculação com diversas variáveis analíticas, o que, para a pesquisa em questão, exigiu algumas adaptações à proposta original, com vistas à melhor compreensão da situação da disciplina no Brasil. No grupo a seguir foram reunidos sob as quatro categorias, os elementos que se julga estarem contemplados nos planos de curso, de forma explícita, denominados elementos iniciais.

- Identidade - compreendendo as variáveis: denominação simples, composta, substitutiva; os objetivos de ensino recorrentes e particulares; o perfil docente, formação inicial e continuada;

- Perfil programático - composto por bibliografia e manuais; e, seleção de conteúdos, nas possibilidades temática, espacial e temporal;

- Presença - referindo-se ao regime de oferecimento, obrigatória e optativa, e, forma de desenvolvimento, anual, semestral ou módulo; e, por fim, carga horária;

- Formas de organização - com respeito às ementas, recorrentes e particulares; e, formas de oferecimento, presencial, semi-presencial e módulos.

Por outro lado, os dados considerados mais complexos, que não estavam claros nos documentos consultados, demandando, assim, a interpretação dos planos ou ainda, outros meios de seleção e coleta de fontes foram chamados de elementos avançados:

1) Identidade - diz respeito a formas de aprendizagem; matriz epistemológica, histórica, histórico-filosófica, sociológica e psicológica; metodologia e recursos didáticos;

2) Perfil programático - referindo-se à avaliação e aos instrumentos avaliativos utilizados na disciplina;

3) Presença - composto pela análise da transdisciplinaridade; dos projetos 
integradores; e dos projetos de ensino;

4) Formas de organização - compreendendo o projeto pedagógico do curso a relação da disciplina com o currículo.

\section{Identidade e perfil programático}

O esforço empreendido neste momento concentra-se na apresentação da disciplina História da Educação na sua perspectiva histórica, da gênese, enquanto "disciplina fundadora das ciências da educação" (NÓVOA, 1994), intimamente vinculada ao processo de profissionalização docente (CARVALHO, 2005), até chegar à análise pretendida sobre a função demandada a essa disciplina, das diversas formas de organização encontradas para isso e dos saberes histórico-educativos necessários à formação do magistério, configurando assim, sua identidade e perfil programático.

\subsection{A denominação como elemento condicionante da identidade}

A denominação da disciplina diz respeito não apenas a sua descrição ou simples identificação mesmo que compondo um grupo diversificado de disciplinas de um currículo, essa seja uma função necessária. Para além do valor distintivo, o nome que o componente curricular apresenta pode contribuir para revelar o lugar, o tempo, o saber e o método de um conhecimento na forma de ensino. Quanto à denominação presente no ensino de História da Educação utilizou-se da tipologia de Santos (2007a), incluindo:

Simples - História da Educação, "reveste um campo de estudo próprio" (SANTOS, 2007a) e expressa o caráter globalizante que pretende assumir. Essa denominação é a mais recorrente dentre os cursos pesquisados, identificada em 72 disciplinas.

Composta - História da Educação Brasileira, presente em 11 disciplinas ou História da Educação Geral e no Brasil em 10 disciplinas. Sob essa denominação, a disciplina assume a organização espacial como referência, ou seja, a disciplina é oferecida de acordo com o lugar que a História da Educação toma como conteúdo. Assim, ao tratar da história da educação no Brasil, a disciplina corresponderá denominativamente a este conteúdo. Nessa definição, a disciplina História da Educação, é por vezes, precedida por complementos que expressam também, a intencionalidade de se contemplar a história da educação local, como por exemplo, História da Educação na Amazônia ou História da Educação Piauiense etc.

Substitutiva - nos planos de ensino pesquisados é representada por: Fundamentos da Educação - 4 disciplinas e Fundamentos Históricos - 4 disciplinas. Há ainda que se registrar outras denominações presentes, que dão ênfase em uma história da educação temática, como História da Educação Infantil, História da Educação de Jovens e 
Adultos, História da Educação Especial entre outros que somam 23 disciplinas.

Quadro 1 - Processo germinativo ${ }^{6}$ da disciplina História da Educação

\begin{tabular}{|c|l|l|}
\hline \multicolumn{1}{|c|}{ Simples } & \multicolumn{1}{|c|}{ Composta } & \multicolumn{1}{c|}{ Substitutiva } \\
\hline 72 disciplinas & \multicolumn{1}{|c|}{21 disciplinas } & \multicolumn{1}{c|}{23 disciplinas } \\
\hline - História da Educação & $\begin{array}{l}\text { - História da Educação Brasileira; } \\
\text { - História da Educação Geral e no } \\
\text { Brasil; } \\
\text { - História da Educação Piauiense. }\end{array}$ & $\begin{array}{l}\text { - Fundamentos da Educação; } \\
\text { - Fundamentos Históricos da Educação; } \\
\text { - História da Educação Infantil; } \\
\text { - História da Educação de Jovens e Adultos; } \\
\text { - História da Educação Especial. }\end{array}$ \\
\hline
\end{tabular}

Na sequência da análise pretendida, apresenta-se a recorrência dos objetivos constantes nos planos de disciplina. Assim, de modo geral, os objetivos apresentam conteúdo íntimo ao desenvolvimento da leitura e da crítica histórica sobre a educação, assumindo o processo educacional enquanto construção histórica, apreendendo a história da educação com vistas a subsidiar a formação de profissionais para o exercício do magistério e da gestão escolar. Em específico, apresentam comumente o intuito de compreender os principais momentos históricos do processo educativo, do Século XVIII até o Século XXI, analisando a contribuição dos grandes educadores para o desenvolvimento da educação no mundo e no Brasil, bem como o objetivo de desenvolver o espírito crítico.

\subsection{O perfil docente como elemento constitutivo da identidade}

O que faz o professor quando ensina? Convida alguém a aprender algo sobre alguma coisa a partir do repertório que ele mesmo forjou de conteúdos, abordagens, ferramentas, materiais, técnicas, enfim de tudo que faz parte de sua cultura profissional, dos seus modos de fazer (NUNES, 2003, p. 117).

Na História da Educação, assim como nas outras áreas acadêmicas, há professores que se dedicam às atividades de docência em sala da aula e, simultaneamente, aos investimentos de pesquisa. Assim, nessa investigação, no que diz respeito ao perfil do docente de História da Educação, limitou-se em conhecer as características acadêmicas básicas dos mesmos. É importante ressaltar, com Nóvoa (1996), que um docente de História da Educação agrega em sua atividade profissional dois elementos importantes - a 
função de historiador e simultaneamente a de professor - o que leva este profissional a transitar pelas aquisições de ambas as áreas, a História e a Educação. Para ele,

O mínimo que se exige de um historiador é que seja capaz de refletir sobre a história da sua disciplina, de interrogar os sentidos vários do trabalho histórico, de compreender as razões que conduziram à profissionalização do seu campo acadêmico. O mínimo que se exige de um educador é que seja capaz de sentir os desafios do tempo presente, de pensar a sua ação nas continuidades e mudanças do trabalho pedagógico, de participar criticamente na construção de uma escola mais atenta às realidades dos diversos grupos sociais (NÓVOA, 1996, p. 417).

No momento presente, parece ser útil precisar o papel do professor de História da Educação no sentido de que a inovação da pesquisa na área e na pedagogia geral possa inundar o dia-a-dia da sala de aula em que a interação pedagógica ocorre. Nesse direção, Justino Magalhães afirma que se espera que os professores fomentem um raciocínio convergente, articulado, integrado e integrador, esclarecido e esclarecedor; um raciocínio fechado em torno de questões conclusivas e, de outro, espera-se que os pesquisadores partam de raciocínios (in)conclusivos, abertos, questionadores, provocativos e divergentes (MAGALHÃES, 1998, p. 10).

A seguir, com objetivo de compor um panorama acerca do perfil dos professores e professoras que ministram História da Educação, é apresentado o Quadro 2, no qual, atento ao perfil profissional acadêmico, identificam-se: o curso de formação inicial; a área de especialização (pós-graduação); a titulação dos docentes da disciplina no momento da coleta dos dados.

Quadro 2 - Formação acadêmica dos docentes da disciplina História da Educação.

\begin{tabular}{|c|c|c|c|c|c|c|c|c|c|c|c|c|c|}
\hline \multirow[b]{2}{*}{ Região } & \multicolumn{5}{|c|}{$\begin{array}{c}\text { Formação inicial } \\
\text { Cursos }\end{array}$} & \multicolumn{3}{|c|}{$\begin{array}{l}\text { Maior } \\
\text { titulação }\end{array}$} & \multicolumn{5}{|c|}{$\begin{array}{l}\text { Área de especialidade } \\
\text { da maior titulação }\end{array}$} \\
\hline & 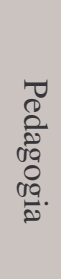 & 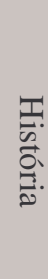 & $\begin{array}{l}T \\
\text { T. } \\
0 \\
0 \\
0 \\
0\end{array}$ & 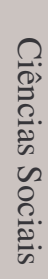 & 声 & 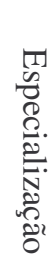 & 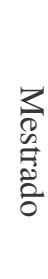 & 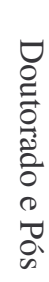 & 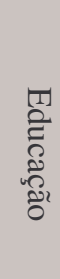 & 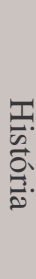 & 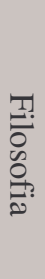 & 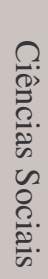 & 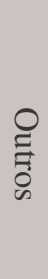 \\
\hline Norte & 05 & 03 & 02 & 01 & 00 & 00 & 07 & 04 & 07 & 01 & 02 & 00 & 01 \\
\hline Nordeste & 14 & 05 & 01 & 01 & 01 & 00 & 07 & 15 & 16 & 04 & 02 & 00 & 00 \\
\hline Centro-Oeste & 06 & 03 & 02 & 00 & 01 & 00 & 03 & 09 & 10 & 02 & 00 & 00 & 00 \\
\hline Sul & 10 & 08 & 02 & 01 & 05 & 00 & 04 & 22 & 17 & 05 & 01 & 03 & 00 \\
\hline Sudeste & 19 & 16 & 04 & 05 & 05 & 02 & 05 & 42 & 33 & 10 & 03 & 02 & 01 \\
\hline Brasil & 54 & 35 & 11 & 08 & 12 & 02 & 26 & 82 & 83 & 22 & 08 & 05 & 02 \\
\hline
\end{tabular}




\begin{tabular}{l|l|l|l|l|l|l|l|l|l|l|l|l|l|l|} 
\% Brasil & 45 & 30 & 9,5 & 5,5 & 10 & 1,4 & 21,7 & 76,9 & 69 & 18,3 & 6,7 & 04 & 02 \\
\hline
\end{tabular}

No que se refere à identificação da área/curso de graduação, a maioria dos docentes tem graduação em Pedagogia, perfazendo 45\%; seguido por História, com 30\%; Filosofia, com 9,5\%; Ciências Sociais, com 5,5\%. Abaixo desses percentuais encontram-se de modo disperso docentes graduados em Psicologia, Letras, Direito, Educação Física, Física e Matemática, representando $10 \%$ do total.

Quando analisada a especialidade do docente, observa-se que: 76,9\% são doutores; $21,7 \%$ possuem o título de mestre; 1,4\% possuem pós-graduação Lato Sensu (Especialização); 69\% dos mestres e doutores desenvolveram dissertações e teses na área de Educação, sendo estes, geralmente, egressos das linhas de pesquisa em História da Educação sob denominações diversas, como: História da Educação; Sociedade, Cultura e Educação; Filosofia e História da Educação; História e Historiografia da Educação; História e Memória; entre outras.

Ainda no grupo de docentes com mestrado ou doutorado, aparecem na segunda colocação, os oriundos dos Programas de Pós-Graduação em História, com cerca 18,3\% dos docentes.

\subsection{Repertórios: bibliografias, conteúdos e metodologias}

No perfil programático da disciplina, encontra-se a bibliografia utilizada nos cursos de História da Educação que, geralmente, gira em torno dos manuais de ensino. O levantamento de títulos contou com inventários apresentados em textos de BASTOS (2006, 2007); NUNES (1996); GATTI JR. (2007); SAVIANI (2008), bem como de consultas complementares as bibliotecas da USP e da UNESP. A partir dos programas recolhidos foi elaborado um ranking dos autores mais indicados nas bibliografias dos planos.

Quadro 3 - Autores e obras mais citadas nos planos de disciplina examinados

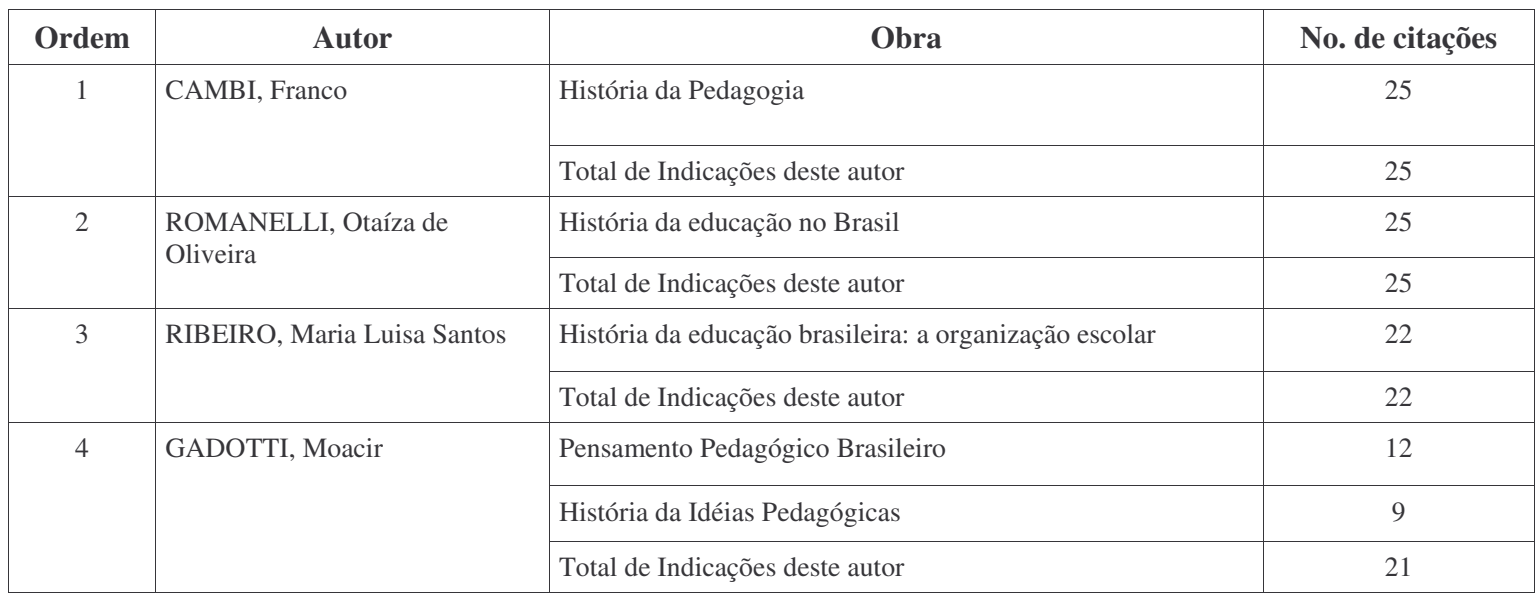




\begin{tabular}{|c|c|c|c|}
\hline \multirow[t]{2}{*}{5} & \multirow{2}{*}{$\begin{array}{l}\text { MANACORDA, Mario } \\
\text { Alighiero }\end{array}$} & História da Educação da Antiguidade aos Nossos Dias & 20 \\
\hline & & Total de Indicações deste autor & 20 \\
\hline \multirow[t]{2}{*}{6} & \multirow[t]{2}{*}{ MARROU, Henri Irénée } & História da Educação na Antiguidade & 19 \\
\hline & & Total de Indicações deste autor & 19 \\
\hline \multirow[t]{2}{*}{7} & \multirow[t]{2}{*}{ ARANHA, Maria Lúcia } & História da Educação & 18 \\
\hline & & Total de Indicações deste autor & 18 \\
\hline \multirow[t]{4}{*}{5} & \multirow[t]{4}{*}{ LOPES, Eliana Marta Teixeira } & Perspectivas Históricas da Educação & 4 \\
\hline & & Origens da Educação Brasileira & 7 \\
\hline & & História da Educação Brasileira & 7 \\
\hline & & Total de Indicações deste autor & 18 \\
\hline \multirow[t]{2}{*}{6} & \multirow[t]{2}{*}{ XAVIER, Maria Elizabeth S. P. } & História da Educação: a escola no Brasil & 16 \\
\hline & & Total de Indicações deste autor & 16 \\
\hline \multirow[t]{2}{*}{7} & \multirow[t]{2}{*}{ GHIRALDELLI JR., Paulo } & História da Educação & 15 \\
\hline & & Total de Indicações deste autor & 15 \\
\hline \multirow[t]{2}{*}{8} & \multirow[t]{2}{*}{ PILETTI, Nélson } & História da Educação & 15 \\
\hline & & Total de Indicações deste autor & 15 \\
\hline \multirow[t]{3}{*}{9} & \multirow[t]{3}{*}{ SAVIANI, Dermeval } & $\begin{array}{l}\text { História e História da Educação: o debate teórico- } \\
\text { metodológico atual }\end{array}$ & 6 \\
\hline & & História e História da Educação & 8 \\
\hline & & Total de Indicações deste autor & 14 \\
\hline \multirow[t]{2}{*}{10} & \multirow[t]{2}{*}{ NISKIER, Arnaldo } & Educação Brasileira 500 anos de história: 1500-2000 & 13 \\
\hline & & Total de Indicações deste autor & 13 \\
\hline \multirow[t]{2}{*}{11} & \multirow[t]{2}{*}{ AZEVEDO, Fernando de. } & A Cultura Brasileira. & 12 \\
\hline & & Total de Indicações deste autor & 12 \\
\hline \multirow[t]{2}{*}{12} & \multirow[t]{2}{*}{ VEIGA, Cyntia Greive } & História da Educação & 12 \\
\hline & & Total de Indicações deste autor & 12 \\
\hline \multirow[t]{2}{*}{13} & \multirow[t]{2}{*}{ ROSA, Maria Glória de } & A História da Educação através dos textos & 11 \\
\hline & & Total de Indicações deste autor & 11 \\
\hline \multirow[t]{2}{*}{14} & \multirow[t]{2}{*}{ LUZURIAGA, Lorenzo } & História da Educação e da Pedagogia & 10 \\
\hline & & Total de Indicações deste autor & 10 \\
\hline \multirow[t]{2}{*}{15} & \multirow[t]{2}{*}{ LARROYO, Francisco } & História Geral da Pedagogia. & 10 \\
\hline & & Total de Indicações deste autor & 10 \\
\hline
\end{tabular}

Fonte: Gatti Jr. (2009).

É importante salientar que na atualidade percebe-se um movimento ainda tímido da adoção de artigos, capítulos de livro e livros que resultam da produção de docentes/pesquisadores da disciplina, sobretudo, daqueles vinculados aos programas de pós-graduação Stricto Sensu, em especial, na área de Educação. Fato este que se deve, em grande medida, ao crescimento e a consolidação das publicações e dos periódicos da área, bem como da disseminação recente de editoras com foco na temática da História da 
Educação ${ }^{7}$.

De modo geral, como assinalado por Faria Filho e Rodrigues (2003), as obras de história da educação, em especial as referenciadas nos planos pesquisados, "[...] tem sido, grosso modo, uma história da educação escolar" (p.165) com destaque para a organização dos sistemas de educação nacionais, as reformas e políticas educacionais, seguidas por incursões sobre o pensamento educacional. Percebe-se também, a miscelânea bibliográfica resultante da indicação de obras de diferentes autores e concepções, revelando em algumas vezes, divergências, que, segundo Faria Filho e Rodrigues (2003, p. 168) “[...] pode, também, denunciar a ausência de referências claras e de obras que as objetivem - e de um mínimo de consenso sobre o que seria importante ensinar em história da educação [...]", sem, no entanto, desconsiderar questões difíceis, a saber: "[...] como trabalhar com um programa que abrange desde o século XVI até as modernas transformações na educação escolar provocadas pelo uso do computador?" (p.167-8).

Quanto ao intercâmbio entre os resultados da pesquisa e a atualidade do ensino, Saviani (2001, p. 2) assinala que a transferência dos novos conhecimentos em História da Educação tem sido pouco significativa, bem como que há indicações de desconhecimento por parte dos alunos tanto da história de modo geral, quanto da história de nossos pensadores e pedagogos particularmente (p. 2).

No que tange a presente investigação, no que se refere à seleção dos conteúdos, os planos pesquisados respeitam uma organização temporal, na qual o delineamento do que será ensinado segue a divisão tradicional usada comumente em História Geral, a saber: Antiguidade, Idade Média, Idade Moderna e Idade Contemporânea, o que desdobra-se em: Educação na Antiguidade; Educação na Idade Média; Educação Moderna; Educação Contemporânea. Esse tipo de organização está presente em 60 dentre as 124 disciplinas pesquisadas, ou seja, em aproximadamente $48 \%$ do total.

Nessa forma de organização podem ocorrer os critérios Epocal ou Cronológico na seleção de conteúdo: o primeiro ocorre de forma a explicitar nos conteúdos as épocas convencionais: Educação na Antiguidade, Educação na Idade Média e assim por diante. Nesse critério, podem ser enquadrados $55 \%$ dos programas de ensino; o segundo ocorre quando uma disciplina familiar ao critério Cronológico, sendo responsável por $45 \%$ do total. É estruturada segundo o modelo tradicional de cronologia, ou seja, o marco divisório para a organização do programa da disciplina é o século, a saber: Educação no Século XVIII, Educação no Século XIX, Educação no Século XX etc.

Outra forma de organização pode incluir a dimensão espacial. Nesse caso, assume relativa importância, o lugar e sua história, com seguintes exemplos: A Educação nas Sociedades Primitivas; A Educação em Roma; A Educação na Grécia; A Educação no Ocidente; A Educação no Brasil. Essa forma de organização está presente em $25 \%$ dos 
programas de disciplina pesquisados. Fazem parte dessa organização, os critérios Local e Regional, dos quais o primeiro caminha para a especialidade de abordagens tanto da própria História da Educação que reconhece o contexto local/regional, tais como, por exemplo, História da Educação na Amazônia ou História da Educação no Triângulo Mineiro e Alto Paranaíba.

Pode-se estabelecer também, uma organização temática em opção a espacial e a temporal. Presente em $27 \%$ do total de disciplinas pesquisadas pode ser exemplificado em a Educação Helênica; Educação Jesuítica; Escolanovismo, mas também: A Educação da Mulher, A Educação Infantil, A Educação de Jovens e Adultos. Por sua vez, essa organização tem como critério, uma seleção global, que se baseia no questionamento dos problemas educativos que orientam o desenvolvimento da disciplina. É importante ressaltar que em alguns casos ocorre uma combinação de um ou dois critérios.

A metodologia de ensino mais utilizada é a expositiva. As técnicas mais comuns são as leituras programadas, os seminários e os debates. Em número menor aparecem técnicas de pesquisa de campo e visitas técnicas. Quanto aos recursos, são mais frequientes, os de tecnologia, como datashow e vídeo. No entanto, é importante destacar que um número muito reduzido de programas traz essas informações, pois, na maioria dos cursos esses dados estão presentes nos planos de aula, aos quais, nessa oportunidade, não houve acesso.

\section{Presença e formas de organização}

A disciplina História da Educação figura nos currículos de formação de professores desde o final do século XIX, com destacada presença na Escola Normal. Atualmente, a disciplina encontra-se vinculada, no caso brasileiro, às licenciaturas e, entre elas, basicamente, ao Curso de Pedagogia.

\subsection{Presença nos currículos}

Nas cinqüenta e cinco instituições de Educação Superior pesquisadas há o oferecimento em regime obrigatório da disciplina. Essa característica pode parecer favorável, mas, em verdade, suscita a necessidade de uma problematização do ensino de História da Educação, principalmente, por experiências em locais nos quais a disciplina passa por momento de descredenciamento dos currículos, assumindo, quando muito, o seu oferecimento optativo, como é paradigmático o caso europeu que, a partir do Tratado de Bolonha (afeto aos países membros da Comunidade Européia), relegou a História da Educação ao caráter de disciplina optativa. 
$\mathrm{Na}$ construção do panorama pretendido sobre o ensino de História da Educação no Brasil obteve-se grande volume de dados dos cursos de formação e das disciplinas. Com isso, optou-se por uma apresentação desses resultados distribuídos regionalmente, de modo a possibilitar algumas comparações. Sabe-se, no entanto, que essa opção de abordagem revela diferenças mais amplas de caráter político, econômico e social, além de imprimir na educação características particulares como oferecimento e acesso à educação superior, estrutura para o funcionamento e condições de trabalho de cada região.

Por meio do quadro obtido, percebe-se que o curso de Pedagogia apresenta carga horária média bastante próxima da mínima exigida, cerca de 3230h, o que reflete no espaço da disciplina História da Educação nos cursos, não maior que 5\% do total, restringido, na média, há dois semestres, com carga horária média de 120h.

De modo geral, não se registrou grandes diferenças entre os cursos e disciplinas das cinco regiões brasileiras. Percebeu-se pouca variação no que se refere à carga horária, a denominação e ao programa de ensino, entre outros indicadores. Demonstra-se assim, a presença de um cenário nacional da História da Educação no qual, entre semelhanças e particularidades, destacam-se: a existência, mesmo que sob várias denominações e formas, do ensino de História da Educação; a oferta em carga horária mínima ou abaixo da média de outras disciplinas; a oferta com sensível incremento da carga horária média nos cursos de Pedagogia na região Nordeste; o aparecimento, com maior frequiência, também na região Nordeste da denominação Fundamentos Históricos e Filosóficos para a disciplina; a oferta com sensível declínio em relação à carga horária e mesmo quanto a oferta da disciplina na região Sudeste; a constatação de que na região Sul está presente a maior relação entre a carga horária da disciplina e do curso, com cerca de $4,8 \%$.

No movimento identificado de expansão da produção acadêmica e da divulgação do conhecimento em História da Educação, são propulsores: os Programas de Pós-Graduação que se instalaram em todo o país e nos quais estão constituídas as Linhas de Investigação em História da Educação que somam 27 dentre os 39 programas pesquisados no âmbito da investigação realizada, com presença da disciplina na totalidade dos Programas pesquisados, independente das linhas de pesquisa dos mesmos, seja na condição de disciplina obrigatória ou de disciplina optativa. Por outro lado, nos cursos de graduação, como afirma Nunes (2003), ocorre que

[...] na discussão das reformulações curriculares, a história da educação, com exceção de poucas instituições, tem perdido espaço para outras disciplinas, cujos professores asseguram trabalhar seus temas a partir de uma perspectiva histórica, como se isso suprisse as necessidades do aluno na construção do raciocínio histórico (p.135-6). 
No discurso que caracteriza esse movimento, a História da Educação tem sua finalidade e necessidade questionada, o que "[...] revela a existência de um sentimento difuso de que essa disciplina está muito distante do que os educadores estão fazendo e experimentando no presente" (NUNES, 2003, p. 136).

\subsection{Regime de oferta e carga horária}

Quanto ao regime de oferta, a disciplina História da Educação é oferecida nos cursos de Pedagogia majoritariamente no regime semestral - 103 disciplinas dentre as 124 analisadas $(83 \%)$. O regime anual está presente em apenas onze cursos, sendo que em dez cursos o oferecimento da disciplina ocorre por meio de módulos, desenvolvidos em três ou seis meses. A seguir, é possível identificar que a carga horária de $60 \mathrm{~h}$ por disciplina é a mais recorrente no regime semestral, presente em $67,9 \%$ do total pesquisado.

Gráfico 1 - Carga horária da disciplina no regime semestral (por semestre letivo)

Variação de carga horária nas disciplinas com oferta semestral (por semestre letivo)

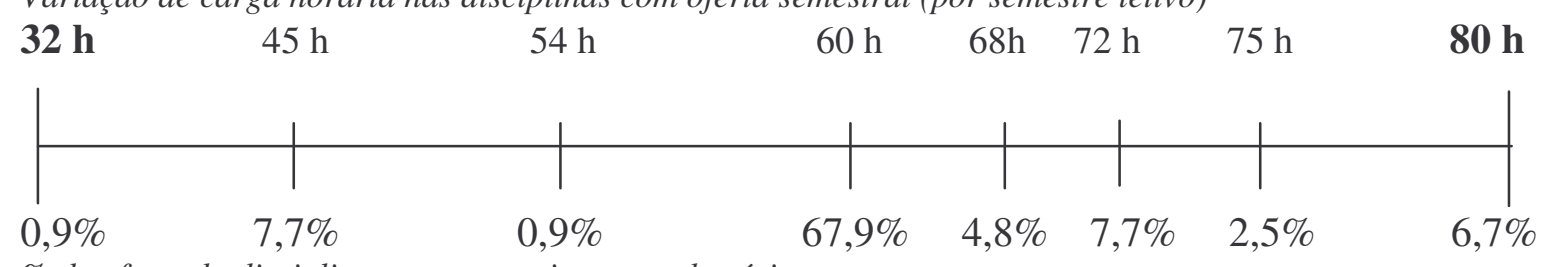

$\%$ de oferta da disciplina com respectiva carga horária

No regime semestral, a disciplina História da Educação é oferecida em três semestres em sete instituições; em dois semestres, em trinta e duas instituições; em um semestre, em cinco instituições.

No regime anual, a maioria das disciplinas apresenta carga horária de $90 \mathrm{~h}$, total de $37 \%$ das disciplinas pesquisadas. A disciplina aparece em três anos em duas instituições; em dois anos em seis instituições; em um ano em uma instituição.

Gráfico 2 - Carga horária da disciplina no regime anual (por ano letivo) 
Variação de Carga Horária nas disciplinas com oferta anual (por ano letivo)

60h $68 \mathrm{~h} \quad 80 \mathrm{~h} 90 \mathrm{~h}$

$120 h$

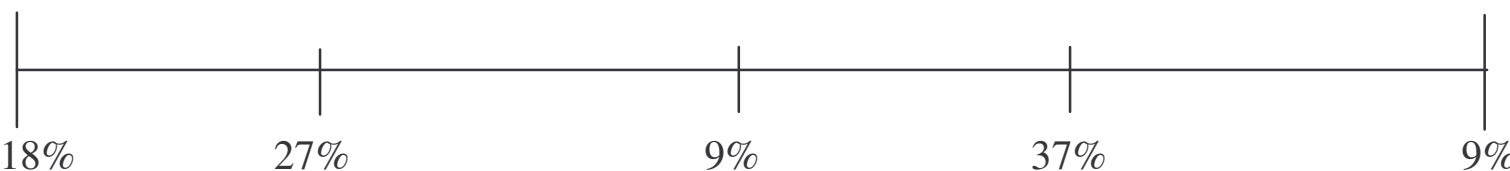

$\%$ de oferta da disciplina com respectiva carga horária

No regime de modular, a disciplina aparece em duas instituições. Em uma delas, localizada na região Sul, a disciplina ocorre em oito módulos durante os quatro anos de curso, com carga horária de $34 \mathrm{~h}$ por componente e, na outra, localizada na região Sudeste, a disciplina é oferecida em dois módulos semestrais de 40h cada.

\subsection{Justificativas apresentadas nas ementas da disciplina}

Quanto às ementas, as disciplinas são justificadas na relação da História da Educação com a História e a Educação, que engloba o estudo das raízes históricas da educação da Antiguidade até os Tempos Modernos, relacionando temas relevantes para a compreensão da educação na atualidade, como o aparecimento e a consolidação da escola na sociedade ocidental e a inserção da escola brasileira nesse processo histórico, a formação dos Estados modernos e a redefinição da escola, da família, da infância e da sociedade. Propõe-se também a compreensão da história da educação com vistas a subsidiar a formação de profissionais para o exercício do magistério e de especialistas em Educação.

Quanto às particularidades presentes nos programas de ensino, destacam-se conteúdos específicos de História da Educação regionalizada, por estados ou mesmo por localidades menores; metodologia de estudo em História da Educação; o aprofundamento em Educação Popular, Didática, Educação no Oriente e História da Educação AfroBrasileira. O foco de particularidade, aqui entendido como variação localizada de conteúdo, ou seja, algo que remete a uma demanda pela História da Educação de determinado local e momento histórico, é reduzida a $8 \%$ das disciplinas, o que pode indicar um ensino de História da Educação com mais de $90 \%$ de conteúdos em comum no Brasil. 


\section{Entre a consolidação e a subsistência nos currículos}

Esta parte do trabalho ocupa-se da situação da disciplina História da Educação após a análise dos elementos condicionantes de identidade, perfil programático, presença e formas de organização, bem como o percurso histórico. Para tanto, são delineadas as categorias consolidação, secundarização, estabilização e subsistência e, por fim, uma análise das influências teórico-metodológicas e técnico-burocráticas compreendidas como elementos delineadores da condição disciplinar do ensino de História da Educação.

\subsection{Consolidação, secundarização, estabilização e subsistência da disciplina}

A disciplina História da Educação transita nos cursos de Graduação e PósGraduação entre a consolidação e a subsistência. Nesse sentido, tornam-se importante para compreensão desse processo as análises presentes nos estudos de Saviani e Lombardi (1999), Saviani (2001 e 2005), Warde (1998) Warde e Carvalho (2000), Nunes (1996, 2002 e 2003), Mendonça (2003), Carvalho (2005), Bastos, Busnello e Lemos (2006) e Fávero (2005) sobre o contexto contraditório existente no que se refere a pesquisa e ao ensino da História da Educação, principalmente pela constatação da ausência de boa parte dos novos conhecimentos alcançados pela pesquisa nas salas de aula e na bibliografia dos cursos (GATTI JR, 2007). No entanto, são muitos os elementos que podem influenciar na situação da disciplina, podendo dar o caráter flutuante entre um extremo a outro. Por isso, foram eleitas quatro categorias possíveis de identificação: Consolidação, Estabilização, Secundarização e Subsistência, conforme apresentadas na figura abaixo:

Figura 1 - Categorias de identificação da situação da disciplina 
1. Consolidada

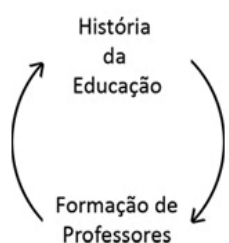

2. Secundarizada

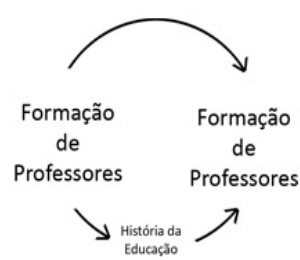

3. Estável

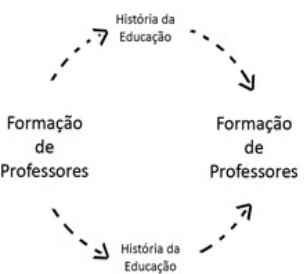

4. Subsistente

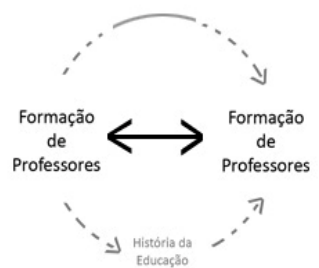

A consolidação da disciplina ocorre quando a História da Educação é identificada como saber especializado, autônomo e reconhecido. Nessa categoria, a disciplina se encontra ativa no currículo e apresenta carga horária equilibrada frente aos demais componentes curriculares. Os conteúdos estão inseridos nos programas de ensino a partir de uma organização espaço-temporal global, com definição de uma perspectiva histórico-antropológica e a organização desses conteúdos ocorre por meio de um corte temático. Os objetivos e as ementas estão construídos em uma base histórico-pedagógica, que propõe o estudo da educação pela história, sem, no entanto, secundarizar nenhuma das áreas, reconhecendo, portanto, as contribuições dos métodos da ciência histórica para o estudo dos problemas da educação. Por sua vez, a disciplina que se encontra nessa categoria tem clareza da filiação a uma matriz epistemológica, geralmente, históricofilosófica ou sociológica.

Um fator importante para a consolidação da disciplina pode estar associada à presença de Programas de Pós-Graduação, com linhas de investigação em História da Educação, o que favorece o intercâmbio acadêmico, já que professores dos Programas provavelmente estão vinculados ao ensino de graduação. Além disso, possibilita a iniciação dos estudantes à pesquisa científica ao campo da História da Educação e, ainda, a atualização de bibliografia, métodos e conteúdos decorrentes da pesquisa desenvolvida sobretudo no âmbito dos Programas de Pós-Graduação (Mestrado e Doutorado).

Reconhecida na categoria secundarização a disciplina é caracterizada pela ocupação por outros setores da educação, tornando a História da Educação especializada, como em História da Educação Infantil, História da Educação de Jovens e Adultos, História da Educação Especial ou ainda, em estágio mais avançado, totalmente substituída, como, por exemplo, em História Social da Criança, História da Infância e História das Creches. Nessa categoria, a importância da disciplina é reconhecida no currículo, no entanto, a sua identidade não é familiar à concepção de História da Educação. Por outro lado, a presença desse tipo de disciplina não extingue o oferecimento de História da Educação, sendo, na verdade, uma disciplina auxiliar de uma vertente de pesquisa aflorada em determinado curso. É nessa categoria que estão presentes as disciplinas sobretudo de 
matriz epistemológica de base psicológica.

Uma disciplina estável é caracterizada pela sua inércia ou pela equilibração dos grupos internos de disputa do currículo. Nesse caso, a disciplina apresenta carga horária igual ou acima de 120h, sua matriz é conhecida, mas não permeia a disciplina, ou seja, não há uma justificativa para a opção por determinada corrente e, isso não transparece na organização da disciplina. Os conteúdos da disciplina estão baseados em uma perspectiva tradicional de História e de Educação. A sua presença no currículo se deve a resistência e não ao reconhecimento da relevância da área para a formação. Nessa categoria, não é possível afirmar que uma disciplina mantém uma filiação clara a uma ou outra matriz epistemológica, fazendo com que circule desde uma perspectiva histórico-filosófica à psicológica, sem, na verdade, saber se reconhecer em alguma delas.

Por sua vez, a subsistência, indica que a disciplina não encontra justificativa para permanecer no currículo e que sua manutenção “[...] remete a sua ténue presença para uma espécie de limbo, onde é tolerada, ou permanece na invisibilidade face a outros campos dominantes" (MOGARRO, 2007 p. 213). Isso pode caminhar para o desaparecimento total da disciplina, já que não encontra sustentação no currículo nem mesmo pelo grupo responsável pela disciplina que se dispõe a assumir outros papéis, outras disciplinas.

Logo, as categorias estabilização e secundarização compõem o campo transitório do estado de disciplina, o qual é representado por elementos que favorecem a não identificação de uma ou de outra nos núcleos extremos: de consolidação ou subsistência. Essa condição intermediária é constituída por forças que se sobrepõem ao campo da História da Educação (ou em qualquer outro campo), tais como a disputa de grupos interessados.

Nesse sistema dinâmico e transeunte representado pela Figura 1 é possível localizar o lugar da disciplina História da Educação. Em alguns casos, esse pode ser o diagnóstico para análise da situação que se encontra a disciplina desde a sua estabilização preocupante até a subsistência confirmada. Em outros, é o reconhecimento do caminho trilhado pela disciplina ao encontro da sua consolidação ou da conformação de sua secundarização. 


\subsection{Novas tendências e alternativas para o ensino da disciplina}

Em algumas das instituições de educação superior pesquisadas estão localizados os processos germinativos indicadores de modelos alternativos para os currículos de Pedagogia e, portanto, para a disciplina História da Educação.

Esses processos ocorrem no momento de constituição da proposta de Projeto desses cursos ou pela necessidade em trânsito de revisão do papel da História da Educação, identificada pelo grupo de docentes da própria disciplina.

Dentre as propostas diferenciadas pesquisadas, podem ser destacadas aquelas que pretendem romper com o modelo tradicional de disciplina, tais como, as propostas de organização do ensino por meio de Módulos, Núcleos temáticos, Modalidade SemiPresencial e de Projetos Integradores.

A organização em módulos é responsável por reunir em uma ou mais disciplinas conteúdos de História, Filosofia e Sociologia da Educação sob o discurso de uma prática interdisciplinar em relação ao conhecimento. Esse modelo foi identificado em dois cursos. A seguir, consta a reprodução do texto de apresentação desse modelo por uma instituição de educação superior pesquisada na região $\operatorname{Sudeste}^{8}$, a saber:

\footnotetext{
Pretende-se a superação da fragmentação do conhecimento pelo desenvolvimento de uma integração entre as diferentes áreas do saber, num movimento e exercício contínuo de distinção e respeito às especificidades, mas também de busca e articulação com aquilo que une e aproxima. No interior de cada módulo estão os temas que serão estudados e que exigem o exercício do diálogo interdisciplinar, uma vez que, quase sempre, pertencem a eixos diferentes.
}

Nesse caso, a História da Educação aparece em dois módulos. No primeiro, a História da Educação compõe um dos três temas, no qual se propõe uma abordagem a cerca da constituição do campo da Pedagogia (filosófico) para isso, busca a reconstituição do trajeto percorrido (histórico) para, já no tempo presente, propor a problematização do campo frente aos desafios (sociológico). Assim, 
Este módulo inicialmente faz uma discussão com os alunos procurando mostrar a especificidade destes três olhares: a história, a sociologia e a filosofia. Em seguida discute a possibilidade e a necessidade de fazer dialogar os três olhares, buscando responder à seguinte pergunta: Como aproximar as contribuições da história, da sociologia e da psicologia para melhor conhecer a realidade brasileira, sobretudo em seus aspetos educacionais? A partir daí faz uma releitura atualizada da investigação histórica, sociológica e filosófica possibilitando, de forma concreta através dos exercícios didáticos propostos, uma compreensão do contexto sócio-político-cultural do país, problematizando as relações entre educação e realidade brasileira.

Consequentemente, na proposta, os "três olhares" são traduzidos em espaços definidos a partir do critério carga horária, a saber: Pedagogia: problematização e constituição do campo (40h); A contribuição da História ao campo da Pedagogia (40h); A contribuição da Sociologia ao campo da pedagogia (40h). Esse modelo caracteriza-se por um processo de aglutinação dos campos de forma intencional a ocupar o lugar dos fundamentos da educação, já que nessa condição, há uma perda de carga horária e, possivelmente, de conteúdo. Aparentemente, o que muda é o momento em que ocorre a fragmentação.

Em outro exemplo da oferta dos conteúdos de História da Educação por meio de módulos propõe-se compreender a constituição e a situação da educação brasileira por meio da integração dos conteúdos intitulados fundamentos da educação, no caso: Filosofia, Sociologia, Psicologia e História.

Este módulo [segundo sua ementa] tem a intenção de aproximar as diversas leituras dos diferentes olhares - da Filosofia da Educação, da História da educação, da Sociologia da Educação e da Psicologia da Educação -, em busca de um entrecruzamento das possibilidades que se articulam e se complementam e que compõem o contexto educacional brasileiro.

Para tanto, procede-se à distribuição temática segundo critério de carga horária, para cada modalidade de fundamentos da educação: A contribuição da Filosofia ao campo da Pedagogia no Brasil (20h); A contribuição da História ao campo da Pedagogia no Brasil (40h); A contribuição da Sociologia ao campo da Pedagogia no Brasil (40h); A contribuição da Psicologia ao campo da Pedagogia no Brasil (20h).

Dado que esse modelo, de ensino por módulos, tem potencial para se tornar significativo no Brasil, em especial, com a emergência de um discurso da formação docente para as séries iniciais mais vinculada a prática pedagógica do que a fundamentação 
teórica, é importante perceber o esvaziamento dos conteúdos que perpassa todas as tradicionais disciplinas vinculadas aos chamados Fundamentos da Educação, reduzindo, desse modo, a reflexão histórica, filosófica, psicológica e sociológica. Ganha espaço, nessa proposta, a discussão prática acerca do mercado de trabalho e dos modelos pedagógicos, descolados do estudo sobre o pensamento pedagógico ou das concepções de educação. Da História da Educação é demandada uma exposição simplificada sobre os processos educativos, especificamente da educação brasileira.

Outro formato que pôde ser percebido refere-se ao de núcleos temáticos que propõe uma organização curricular em que os conteúdos são "pulverizados" ao longo do curso. Nessa perspectiva, a carga horária da disciplina é distribuída em uma série de disciplinas de curta duração. Esse modelo foi identificado em dois cursos. A título de exemplo, a estrutura de um desses cursos, no que diz respeito à História da Educação ${ }^{9}$, a saber: História da Educação e da Pedagogia (34 h), História das Instituições Educacionais (34 h), História da Educação no Brasil: Colônia (34 h), História da Educação no Brasil: Império (34 h), História da Educação no Brasil: República (68h), História da Educação Pública (34 h), História da Infância no Brasil (34 h) e História do Pensamento Educacional $(34 \mathrm{~h})$.

A proposta aparente esperar que todos os eixos (período/série) sejam contemplados com as diferentes contribuições em conjunto com o desenvolvimento de atividades de formação prática. Os núcleos temáticos estão por sua vez, inseridos nos eixos integradores, que sistematizam todas as disciplinas acerca de um objeto comum, que pode ser, por exemplo, a formação docente, a educação brasileira etc.

A partir da flexibilização curricular regulamentada na Portaria 2.253 do Ministério da Educação (MEC), alguns cursos utilizam a carga horária de $20 \%$ dos cursos em atividades semi-presenciais. O MEC, no entanto, preconiza o cuidado de não utilizar tal recurso como forma de aligeirar o desenvolvimento do curso. Além disso, as atividades semi-presenciais podem ser responsáveis pelo aperfeiçoamento do conhecimento tecnológico bem como da crítica dos seus usos.

Como orientação do Ministério da Educação, na tentativa de promover a integração e a interdisciplinaridade dos cursos de graduação, foram introduzidos em várias instituições mecanismos de intercâmbio entre as disciplinas. Dos modelos observados são os mais frequentes os Projetos Integradores que consistem em atividades conjuntas interligadas a vários campos de determinada formação. Nesse mecanismo, cabe destacar a oportunidade que a História da Educação conquista de renovar a sua importância para o currículo e apresentar as possibilidades de se interagir com os outros componentes não apenas na posição de subsidiadora ou de subserviência, mas de problematizadora da educação. 
Por fim, na pesquisa empreendida, foram observados nos programas de disciplina, alguns indicativos, mesmo que em número pequeno, da promoção de experiências diferenciadas aos alunos diante do conhecimento histórico educativo. Por exemplo, a abordagem do conteúdo de História da Educação por meio do teatro, da visita de campo, da pesquisa biográfica, da entrevista, dos arquivos escolares, das bibliotecas e dos impressos ${ }^{10}$.

\section{Apontamentos sobre questões de Currículo}

O currículo, segundo a perspectiva crítica, é antes de tudo uma relação de poder e um campo de disputas. Nessa perspectiva, Tadeu Tomaz da Silva argumenta que em última instância "[...] um currículo busca precisamente modificar as pessoas que vão 'seguir' aquele currículo", logo, torna-se necessário enfrentar questões como: "o que elas devem saber? Qual conhecimento importante ou válido ou essencial para merecer ser considerado parte do currículo?" (SILVA, 1999, p. 14-15).

Nesse sentido, a História da Educação, assim como as demais disciplinas, não escapa aos questionamentos de utilidade, finalidade e necessidade que podem frequentar os debates em torno de uma proposta ou reforma curricular, marcadas pela existência de um movimento crescente de afirmação, ocupação e consolidação de novos campos ou recortes temáticos, cada vez mais segmentados e especializados à medida em que promovem a subtração, substituição e extinção de outros, de perspectiva ampla, muitas vezes tidos como clássicos.

Nos currículos dos cursos Normal e de Pedagogia no Brasil, a História da Educação foi ao longo da história, objeto frequente de disputas, exemplo disso, foi o seu oferecimento como apêndice da Filosofia da Educação por vários anos (WARDE, 1998) ou o caráter secundário destinado à disciplina, segundo uma perspectiva de ênfase nos estudos da Biologia, Sociologia e Psicologia (CARVALHO, 2005) . Dessa forma,

\footnotetext{
A História da Educação carrega uma marca que lhe é conformadora: a de ter nascido para ser útil e para ter sua eficácia medida não pelo que é capaz de explicar dos processos históricos, mas pelo que oferece de justificativas para o presente e de guia para o futuro. (WARDE, 1998, p.91).
} 
Assim, a História da Educação tem presença marcada nas disputas de currículos, seja por status em determinado momento e atualmente, por espaço nos cursos de formação de professores. Por outro lado, observa-se, a partir do levantamento dos planos de ensino, que a disciplina oferece, ao menos no sentido de proposição, uma contribuição sólida para o futuro profissional dos educadores, seja por meio do desenvolvimento da capacidade de pensar historicamente a realidade educacional, seja pelo repertório de histórias do campo educativo necessários à problematização da atualidade. No entanto, algo entre a idealização no plano e a efetivação no ensino indica que tais objetivos nobres à História da Educação, de modo geral, não conseguem se traduzir no reconhecimento da permanência da disciplina na estrutura curricular.

\section{Considerações finais}

Ao final deste trabalho é importante destacar que ao propor a análise quanto à situação atual da disciplina nas categorias de consolidada, secundarizada, estável ou subsistente pretendeu-se explorar as condições e caminhos responsáveis pela indicação em uma ou outra situação, respeitando as particularidades de cada curso. Nessa direção, a semelhança do que foi constatado por Mogarro (2007), a predominância de "[...] uma organização desses planos de curso segundo a lógica da história das idéias educativas e do pensamento pedagógico, inseridas num tempo longo que se estende da Antiguidade à Escola Nova" (p.215). No caso brasileiro, estendendo-se ao Regime Militar (1964-1985). Nessa direção, encontram-se privilegiadas as abordagens histórico-educativas marcadas pelas reformas educacionais empreendidas no Brasil, desde a Colônia, com as Reformas Pombalinas (1759-1772) até a Lei de Diretrizes e Bases de 1961, bem como as reformas: Universitária, em 1968; de $1^{\circ}$ e $2^{\circ}$ Graus, em 1971.

De modo geral, pela característica da amostra trabalhada - universidades, na maioria, públicas, com programas de pós-graduação em educação instalados - observou-se que a disciplina História da Educação encontra-se consolidada, com carga horária equilibrada frente aos outros componentes curriculares, matriz epistemológica definida, na maioria, histórica ou histórica-filosófica, sob responsabilidade de docentes com elevada formação e atuação nos cursos de mestrado e doutorado.

Porém, quanto à proposta de análise da situação da disciplina História da Educação, sistematizada em quatro categorias (consolidada, secundarizada, estável e subsistente) e, diante de todas as possíveis correções metodológicas, uma parece ser inadiável, a presença de uma quinta categoria: inexistente. Situação já encontrada em outras partes do mundo e que começa dar indícios de possível concretização no Brasil, pois a disciplina História da 
Educação nos cursos de Pedagogia brasileiros não está imune às pressões por cursos de formação em tempo cada vez mais reduzido, caracterizando uma formação aligeirada, recorrendo em muitas vezes, à diminuição de carga horária das disciplinas. Constata-se a probabilidade de que a História da Educação, assim como outras disciplinas tidas como "teóricas", ceda mais espaço ao processo de enxugamento dos cursos do que outras disciplinas de caráter mais "prático".

Quanto a isso, Nunes (2003) aponta alguns dos problemas pertinentes ao ensino de História da Educação, principalmente, aqueles ligados ao reconhecimento do saber histórico-educacional como contribuidor para a formação. Uma das questões básicas é o tratamento do conteúdo tido em muitas vezes como denso, fastidioso, enciclopédico, levando ao questionamento do sentido de aprender História da Educação. Quanto a isso, os planos demonstram, de início, a necessidade de repensar a amplitude do conteúdo a ser apresentado em espaço limitado de tempo dedicado à disciplina, muitas vezes, sob a abordagem linear da história da educação que obriga percorrer, segundo a ordem cronológica, da Antiguidade até a Modernidade, do Mundial ao Regional/Local em um ou dois semestres.

Por isso, para a disciplina História da Educação está posto o desafio de que se torne transformadora da consciência e da ação educativa pela via do conhecimento histórico. Esse movimento é também uma necessidade para que a disciplina não se torne obsoleta, apenas a fim de cumprir a carga horária dos currículos, ou pior, ceder lugar para outras disciplinas ou tendências que volta e meia tomam os processos de formação docente.

Outra consideração importante, diz respeito ao título deste trabalho, que não desistiu em assumir a intenção de tratar a disciplina História da Educação enquanto campo do saber inerente à formação de professores, seja nos anos iniciais do Ensino Fundamental, seja de História, Matemática, Biologia etc. Entretanto, a oferta reduzida da disciplina nesses cursos, levou ao protagonismo quase exclusivo do curso de Pedagogia nas análises que por sua definição corrente, engloba pedagogos professores e profissionais em outros cargos da educação escolar e não escolar.

Por fim, pode-se dizer que a variedade com a qual a disciplina História da Educação é ofertada nos cursos de Pedagogia pode ser o caminho a garantir a sua presença e a sua renovação, com a preocupação de "[...] pensar no justo equilíbrio entre inovação e tradição e [deixando] de considerar que a novidade é, por si só, positiva e benéfica para a formação" (FARIA FILHO e RODRIGUES, 2003, p. 173). Assim, a disciplina se aproximaria e dialogaria com os outros componentes do currículo com a finalidade de contribuir mais efetivamente para a formação dos professores. Um passo importante é trazer a atividade de pesquisa que tanto contribui para o campo da História da Educação para a graduação, traduzida em incentivos à iniciação científica e ao estabelecimento de uma estreita relação entre a graduação e pós-graduação Lato e Stricto Sensu. 


\section{Referências}

BASTOS, Maria Helena Câmara (2006). Uma biografia dos manuais de História da Educação adotados no Brasil (1860-1950). VI CONGRESSO LUSO-BRASILEIRO DE HISTÓRIA DA EDUCAÇÃO. Anais. Uberlândia/MG, p. 334-49.

. (2007). Pedagogia e Manuais: leituras cruzadas. Os Manuais de História da Educação Adotados no Brasil (1870-1950). Impresso. Porto Alegre: Pontifícia Universidade Católica do Ro Grande do Sul. 24p.

CARVALHO, Marta Maria Chagas (2005). Considerações sobre o Ensino da História da Educação no Brasil. In. GATTI JR, Décio; INÁCIO FILHO, Geraldo (Orgs.). História da Educação em Perspectiva. ensino, pesquisa, produção e novas investigações. Campinas, SP: Autores Associados; Uberlândia, MG: EDUFU. p. 33-46.

ESCOLANO BENITO, Augustín (1994). La investigación historico-educativa y la formación de profesores. Revista de Ciencias de la Educación. n. 157. p. 55-69.

FARIA FILHO, Luciano Mendes de; RODRIGUES, José Roberto Gomes. (2003) A história da educação programada. Uma aproximação da História da Educação ensinada nos cursos de Pedagogia em Belo Horizonte. Revista Brasileira de História da Educação. n. 6. jul./dez. p. 159-175.

FÁVERO, Maria de Lourdes de Albuquerque (2005) Reflexões sobre o Ensino e a Pesquisa da História da Educação Brasileira. In: GATTI JR., Décio; INÁCIO FILHO, Geraldo (orgs.). História da Educação em Perspectiva: ensino, pesquisa, produção e novas investigações Campinas/SP:Autores Associados, Uberlândia/MG:Editora da Universidade Federal de Uberlândia. p. 47-67.

GATTI JR, Décio (2004). A escrita escolar da História: livro didático e ensino no Brasil (1970-1990). Bauru/SP: Edusc, Uberlândia/MG, Edufu.

. (2007). Percurso histórico e desafios da disciplina História da Educação no Brasil. In. GATTI JR., Décio; PINTASSILGO, Joaquim (Org.) Percursos e desafios da pesquisa e do ensino de História da Educação. Uberlândia: EDUFU. p. 99-139.

(2009). Investigar o Ensino de História da Educação no Brasil: categorias de análise, bibliografia, manuais didáticos e programas de ensino (Séculos XIX e XX) In. GATTI, JR. Décio; MONARCHA, Carlos; BASTOS, Maria Helena Camara. O Ensino de História da Educação em Perspectiva Internacional. Uberlândia: EDUFU, p. 95-130.

. (2010) Aspectos teórico-metodológicos e da historiografia brasileira na temática da história das disciplinas escolares (1990-2008). Tempos e Espaços em Educação. v.1, n.1, p. 9-30.

MAGALHÃES, Justino (1998). Fazer e Ensinar História da Educação. In. Fazer e Ensinar História da Educação. Braga, Portugal, LUSOGRAFE. Universidade do Minho, p. 9-33.

MENDONÇA, Ana Waleska Pollo Campos (2003). Entrevista. Ícone Educação. v. 9. n. 1 e 2. p. 7-12. 
MOGARRO, Maria João (2007). A História da Educação nos Currículos de Formação de Professores: consolidar a História da Educação, pela construção de identidades. In. PINTASSILGO, J.; ALVES, L. A; CORREIA, L. G. e FELGUEIRAS, M (Orgs.) A História da Educação em Portugal: balanços e perspectivas. Porto: Asa. p. 203-228.

NÓVOA, António (1994). História da Educação. Relatório da disciplina História da Educação, apresentado no âmbito das provas para obtenção da agregação. [Impresso] Faculdade de Psicologia e de Ciências da Educação da Universidade de Lisboa.

(1996). História da educação: percursos de uma disciplina. Análise Psicológica. Lisboa, Portugal, 417-434.

(1999). Apresentação. In: CAMBI, Franco. História da Pedagogia. São Paulo: Editora da Universidade Estadual Paulista. p. 11-5.

NUNES, Clarice (1996). Ensino e historiografia da educação. Problematização de uma hipótese. Revista Brasileira de Educação. Jan/Fev/Mar/Abr $\mathrm{N}^{\circ} 1$ p.

. (2002). Entrevista. Ícone Educação. v. 8, n. 1 e 2. p. 5-14.

. (2003). O ensino da história da educação e a produção de sentidos na sala de aula. Revista Brasileira de História da Educação. n. 6. jul./dez. p. 115-57.

SANTOS, Maria Teresa (2007a). Perfil da História da Educação: conflitos entre o empobrecimento efectivo e o potencial objectivo. In. PINTASSILGO, Joaquim; ALVES, L.A; CORREIA, L.G. e FELGUEIRAS, M (Orgs.) A História da Educação em Portugal: balanços e perspectivas. Porto: Asa. p. 229-256.

. (2007b). Percurso e Situação do Ensino de História da Educação em Portugal. In: GATTI JÚNIOR, D; PINTASSILGO, J. (Orgs.) Percursos e desafios da pesquisa e do ensino de História da Educação. Uberlândia: EDUFU. p. 75-97.

SAVIANI, Dermeval (2001). História da Educação e Política Educacional. Revista HISTEDBR On-line. n. 3. Disponível em http://www.histedbr.fae.unicamp.br/art2_3.html (Acessado em 01/11/2010).

(2005). Reflexões sobre o Ensino e a Pesquisa em História da Educação. In: GATTI JR., Décio e INÁCIO FILHO, Geraldo (orgs.) História da Educação em Perspectiva: ensino, pesquisa, produção e novas investigações Campinas/SP:Autores Associados, Uberlândia/MG:Editora da Universidade Federal de Uberlândia. p. 7-31.

. (2008). História da História da Educação no Brasil: um balanço prévio e necessário. EccoS - Revista Científica, v.10, Especial, p. 147-67.

SAVIANI, Dermeval; LOMBARDI, José Claudinei (1999). Sobre a Pesquisa e o Ensino de História da Educação Brasileira. Boletim "História, Sociedade e Educação". Ano I, n. 2. Disponível em http://www.histedbr.fae.unicamp.br/boletim12.doc (Acessado em 01/11/2010).

SILVA, Tomaz Tadeu da (1999). Documento de Identidade: uma introdução às teorias do currículo. Belo Horizonte: Autêntica. 
WARDE, Mirian Jorge. (1998). Questões Teóricas e de Método: a História da Educação nos Marcos de uma História das Disciplinas. In. SAVIANI, D; LOMBARDI, J.C; SANFELICE, J. L. (Orgs.) História e História da Educação: o debate teórico metodológico atual. Campinas: Autores Associados, HISTEDBR. p. 88-99.

WARDE, Mirian Jorge e CARVALHO, Marta Maria Chagas de (2000). Política e Cultura na Produção da História da Educação no Brasil. Contemporaneidade e Educação. v. 5, n. 7. p. 9-33.

\section{Notas}

\footnotetext{
${ }^{1}$ Trabalho que comunica parte dos resultados alcançados no desenvolvimento da investigação intitulada "Lugares, Tempos, Saberes e Métodos de Ensino da Disciplina História da Educação na Formação de Professores no Brasil Contemporâneo (1930-2000)", desenvolvida entre 2007 e 2010, com o apoio do Conselho Nacional de Desenvolvimento Científico e Tecnológico (CNPq) e da Fundação de Amparo à Pesquisa do Estado de Minas Gerais (FAPEMIG). O projeto está inserido nas atividades do Grupo de Estudos e Pesquisas sobre a Disciplina História da Educação (GEPEDHE), liderado por Décio Gatti Júnior, da Universidade Federal de Uberlândia (UFU) e por Carlos Roberto da Silva Monarcha, da Universidade Estadual Paulista "Júlio de Mesquita Filho" (UNESP).

${ }^{2}$ Graduado em Pedagogia e mestrando em Educação na Universidade Federal de Uberlândia. E-mail: brunogoncalvesborges@hotmail.com

${ }^{3}$ Doutor em Educação - História e Filosofia da Educação - pela Pontifícia Universidade Católica de São Paulo (PUC-SP). Professor Associado III da Universidade Federal de Uberlândia (UFU). Bolsista de Produtividade em Pesquisa do CNPq - Nível 1D. Membro da Câmara de Ciências Sociais, Humanas, Letras e Artes (SHA) da FAPEMIG. Editor dos periódicos "Educação \& Filosofia" e "Cadernos de História da Educação". E-mail: degatti@ufu.br

${ }^{4}$ De um universo de 55 instituições de educação superior pesquisadas, a disciplina História da Educação foi identificada em: $100 \%$ dos cursos de Pedagogia; 3,3\% dos cursos de História; 5,5\% das demais licenciaturas agrupadas.

${ }^{5}$ Relação de cursos nos quais houve investimento na busca por planos de ensino da disciplina História da Educação: Ciências Biológicas, Educação Física, Filosofia, Geografia, História, Letras, Matemática, Química e Sociologia.

${ }^{6}$ Termo empregado por SANTOS (2007a).

7 A esse respeito cabe destacar algumas iniciativas importantes promovidas pelas editoras: Autores Associados (Campinas/SP), Autêntica (Belo Horizonte/MG), Editora da Universidade Federal de Uberlândia (Uberlândia/MG), Editora UNESP (São Paulo/SP), Editora da Universidade São Francisco (Bragança Paulista/SP), Vozes (Petrópolis/RJ), Editora da Universidade do Estado do Rio de Janeiro (Rio de Janeiro/RJ), Cortez (São Paulo/SP), Ática (São Paulo/SP), entre outras.

8 As informações são provenientes do projeto pedagógico do Curso de Pedagogia de instituição de Educação da região Sudeste do Brasil.

9 As informações são provenientes do projeto pedagógico do Curso de Pedagogia de instituição de Educação da região Sul do Brasil.

${ }^{10}$ Trata-se, por exemplo, de experiências constantes nos programas de ensino de instituições de educação superior da região Sudeste e Nordeste.
}

Artigo recebido em: 03/12/2010

Aprovado em: $\quad$ 18/12/2010 